\title{
Inquiry-Guided Learning In A Management Of Technology Environment
}

Helmut H. Hergeth, (E-mail: hhh@ncsu.edu), North Carolina State University

Gary W. Smith, (E-mail: gsmith@tx.ncsu.edu), North Carolina State University

\begin{abstract}
Inquiry-guided learning is a teaching technique that encourages active participation of students and, in addition to better retention, such learning is credited with promoting critical thinking, sourcing information, organizing information, promoting self learning and enhancing the life-long learning experience.

In applied degree programs where technology and management courses run parallel, different tools must be used to involve students and tie in real life scenarios to prepare students for opportunities in industry, government, and society.

This paper describes how data is sourced, prioritized, organized, and presented in priority and audit tables. It also demonstrates simulation board games as teaching tools in textile management and technology curricula. A simulation board game is used to practice decision making tools and skills in a team environment. Audit tables are used to detect and correct potential sources of quality problems.
\end{abstract}

\section{Introduction}

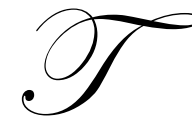

he College of Textiles at NC State University provides an education in both technology and management. This provides simultaneously challenges and opportunities to the instructors as students have to change focus on a regular basis. Integrating both aspects of the students' education is a valuable objective and contributes to continued high placement rates of the college's graduates. In order to increase praxis relevance and teach students how their college education links to their future work environment, Drs. Smith and Hergeth participated in a two-semester training session on "Teaching with Inquiry-Guided Learning" during the Spring and Fall of 2002. The training sessions were held by the Faculty Center for Teaching \& Learning at NC State and lead to some adjustments in course design. This paper looks at the integration of Inquiry-Guided Learning in a typical management and in a typical technology type course.

\section{Inquiry-Guided Learning}

Inquiry-guided learning promotes student learning through guided investigation of problems or questions. The goal is to lead students towards investigating such problems more and more independently (FCTL, 2002). At the same time it is expected that students retain the material better because it has been applied rather than presented only in an abstract manner (Wiggins and McTighe, 1998), and it enhances general problem solving and reflective thinking skills, which has long been a desired outcome in most curricula (e.g., Bransford and Stein, 1984, Lee, 1998/1999).

Like most curricula, the textile management and textile technology curricula are faced with trying to cover a lot of material, so that fast understanding is considered a benefit. If students can work independently, e.g., research and analyze a problem without an instructor micromanaging each step, learning becomes less frustrating for both the instructor and the student. Inquiry-guided learning prepares the students to seek information needed to solve their problem rather than trying to absorb information that they have no real use for at the time it is presented. 
Depending on the specific course content, different methods must be applied to integrate inquiry-guided learning into the course, and there are also some limits to what is practical or feasible within a classroom setting. For example, theoretically it would make sense to have textile students manage a sample company and solve all technical and managerial problems that arise. Yet this would not be efficient education from a financial or time perspective. It would also neglect some of the reflective aspects of learning. Therefore it is more feasible to integrate model scale experiences and problems into courses, so that students are allowed to solve problems and to reflect about their solutions.

\section{Board Game Simulation}

Within the scope of management education in the textiles curricula, financial management and understanding financial statements is an important topic. Yet financial management involves some accounting, and accounting in itself is an abstraction of business or commercial activity. Therefore, no matter how concrete and real the presented examples in class are, they are still abstract from the actual business activity.

Business simulations offer the possibility to provide real business problems or scenarios, and to focus the attention to specific aspects that are relevant to the class. Just like in a flight simulator, participants can experience typical and less typical situations without actually risking a company or plane (Hergeth, 2003, Jones \& Hergeth, 2002) and without the instructor having to wait for a specific situation arising. Learning through trial and error using first-hand experiences (e.g., learning to ride a bike) is replaced in higher education by substituting direct experiences through cases, simulations, or experiments (Romme \& Putzel, 2003, and further literature there, e.g., Hassal \& Joyce, 1997, Klabbers, 2001, Wolfe \& Fritzsche, 1998).

Simulations or models can have different degrees of abstractness, and as such serve different purposes. Mathematical models and computer based models tend to be rather abstract from reality, and their purpose lies in running many iterations to find certain types of solutions. Participants tend to be less emotionally involved. Board games tend to be closer to reality with respect to the participants' emotional involvements, but they tend to abstract from some of the details of reality. In addressing strategic issues it is useful to present students with the "big picture" and less detail. At the same time strategic issues need to be discussed rather than repeated in many iterations, since later on in real life the students will not have to opportunity to "try out" hundreds of decisions on capacity expansion or marketing strategy.

In the textile management curricula the Game of Income/Outcome ${ }^{\mathrm{TM}}$ is used to introduce students to business decisions and their financial impact. During the simulation participants have the opportunity to make decisions on all critical aspects of a business, including marketing, operations, and finance. At the same time they have to keep track of the financial impact of these decisions by keeping books and creating financial statements at the end of each term. By basing the financial statements on decisions made by the participants, they experience the results rather than looking at and analyzing somebody else's results. The abstract tool of accounting has a real story attached to it that was influenced by the participant.

During the simulation session, students form teams that run companies that compete against each other in the market place. This is a realistic problem, and the students have the opportunity to explore ways of competing within the legal framework of the simulation. At the end of each round, financial statements provide specific feedback on each company, and the facilitator has the opportunity to review the reasons and impacts of these results. Management tools like cash flow forecasts, budgets, break-even analysis, and cost analysis can be introduced, and their value becomes obvious during the simulation.

The instructor of the course becomes truly a facilitator and guide for participating students as they try to explore how to address business problems and how to best compete. This becomes obvious by the fact that many of the participants start to ask about certain tools before they are mentioned in the script. Good facilitation is needed to also address less typical inquiries based on specific industries or economic situations. Board game models allow exploring new solutions and analyzing how they would play out in the financial statements of the company. In some of these situations facilitator and participants start to explore together. 
During the session, some aspects of business finance will always be covered. The dynamics between profitability and cash flow and the impact of any business activity on financial statements is explored and understood rather than just read. Since students are working in teams, there is a lot of discussion and questioning, which helps to understand topics deeper. By using the business simulation in the beginning of the semester, the dynamics of inquiry and exploration can set the tone for learning for the rest of the course. Intuitively this seems beneficial, but at this time no assessment of the benefits has been conducted.

\section{Income/Outcome ${ }^{\mathrm{TM}}$ Description}

The game of Income/Outcome $\mathrm{TM}^{\mathrm{TM}}$ is a team-based competitive business simulation with several teams of typically 3 to 5 participants. Each team sits at their own table, running their own model of a company in direct competition with the other teams in the room. The teams compete in a closed bid market place for orders from the facilitator (Andromeda, 2003). During the simulation the teams make decisions about marketing, pricing, production, finance, quality, etc., and balance cash flow and profitability. At the end of each round they do their books and present financial statements. There is no element of chance by use of dice or hidden computer simulations, so every result and number on the financial statements can be directly traced to a decision by the team or action in the market place.

During each round the facilitator presents management tools and relates them to the simulation. These tools are then immediately used by the teams and applied to their company situation. After presenting new tools or information, the facilitator checks with all teams and acts as a resource for information they may be seeking.

At the end of each round and after the program the facilitator debriefs all teams. This leads to discussions of what determines a "winner", the use of financial ratios, and examples of real life applications.

\section{Outcomes Of Using Board Simulations}

Goal of using inquiry-guided learning techniques is not simply to make financial statements more fun, but to allow students to self-teach and explore, to promote critical thinking, and hopefully to promote lifelong learning.

For facilitators and observers it becomes very obvious that students self-teach and explore during the income/outcome ${ }^{\mathrm{TM}}$ game sessions while they discuss intensely and direct questions to the facilitator. As long as the direction of questions comes from students to the facilitator, students are motivated and inquisitive. During the preparations of financial statements at the end of each round, students explain to each other and inquire from each other how to perform the necessary calculations. This promotes better understanding than copying lecture presentations, and in a corporate setting it can also help better understand corporate culture and structure (Kriz, 2003).

In addition to such observations of behavior and activity during the session by the facilitator or a visitor, participants typically have the opportunity to provide feedback on content and facilitation. Within the College of Textiles student feedback was used to determine what key learning outcomes were addressed by the program, and when in the curriculum the simulation was best placed. While originally placed in two upper level courses (junior level marketing course and senior level strategy course), students indicated that the applied information from the program would be valuable before taking a traditional accounting class or financial management class. The program is now integrated into a second year introductory management course ("Business of Textiles") that is taken by all textile management students as well as all textile technology students. Further research is planned to evaluate what impact the program has on results in the now following accounting and financial management courses. Many students also commented about gaining better understanding about the interaction of different aspects of business and how many different things they needed to consider. This is an aspect of learning that is very difficult to cover in lecture format, and if introduced at all, rarely has the same impact as actually doing and experiencing it.

Feedback on the program from industry participants includes generic better understanding of general and specific aspects of business, but also increased respect for other departments and their activities. By learning is this 
problem-guided environment participants are not only learning specific skills and concepts through doing, but they are also learning through interaction with other participants.

For corporate programs it is also possible to display the participants' company in financial terms on the board and lead a discussion about how some of the learned concepts apply to the actual company that the participants work in. This gives the business model of the simulation an additional layer of reality and shows participants how business concepts and tools relate to their actual corporate reality. This leads to questions from participants about business concepts not only how they relate to the simulation but also how they relate to their company environment. One of the desired goals of inquiry-guided learning is the promotion of independent research and investigation, and this step allows students and participants to do just that. The inquiry is motivated and driven by the student rather than the facilitator.

\section{Audit Tables}

It is important to give students an insight into practical problems and "real life" approaches to technical problem identification, solution and/or prevention. As such, students need to develop the problem identification and solution skills as quickly and as efficiently as possible.

In the approach to be discussed, it is normal practice to form a group having 3 student members at the beginning phase of a course involving problem identification and solution exercises and then later to have each student utilize approaches and skills obtained to undertake exercises on their own to develop confidence in their identification, sourcing, organization and development skills.

Table 1 is the result of one student assignment and documents an attempt to define typical factors that promote the generation of short fibers or lint in a typical knitting factory that produces such products as t-shirts and golf shirts. In inquiry-guided learning, a defined problem could be given to students but in other cases, students could be asked to define their own concept of a problem and follow a similar approach to the approach that will now be discussed. In the exercise that led to the development of Table 1, a student (Miguel Andreu Marin) was given the task of sourcing and then documenting a minimum of 50 parameters that could promote the formation of short fibers. During the orientation meeting, Miguel was asked to brainstorm for ideas and then document a list of potential causes. In terms of assignment format, all potential causes were to be defined on his own time and had to be documented in one Table using the following guidelines: (1) all potential causes of lint generation had to be grouped into no fewer than 4 groupings, (2) each parameter had to be stated in 4 words or less, (3) the Table had to have a clearly defined title and clearly defined sub-titles, (4) the name of the Company and his name had to be documented. The Table of parameters was to be submitted no later than 1 week after the assignment was given.

In the preliminary meeting, he was also told that although there are many forms of contamination, lint generation and the associated problem of fiber contamination are two of the problems which cause severe problems for knitters in terms of: (1) product quality, (2) cost, (3) productivity, (4) machine load, (5) maintenance and (6) company reputation.

Once the list of parameters in Table 1 had been submitted and discussed as to the merits of the parameters listed, other potential parameters were discussed before step 2 of the process was introduced.

Although an example of step 2 of the process is not documented in this paper, Miguel was then asked to prioritize his groupings of parameters so that the most benefit could be obtained at the least cost in the fastest time frame. Once "group" prioritization had been decided then a follow-up Table was requested which would document actions for each parameter that could be taken to minimize or prevent the generation of lint. 
Table 1: Typical Factors Promoting Lint Generation

The Jersey Knitting Company

Raleigh, N. C., 27695

(Miguel Andreu Marin)

Yarn
\begin{tabular}{|l|l|l|}
\hline 1. Blend & 2. Staple length & 3. Fiber recycling \\
\hline 4. Fiber maturity & 5. Micronaire & 6. Twist \\
\hline 7. Yarn count & 8. Yarn type & $9 . \%$ C.V. \\
\hline 10. Classimat majors & 11. Lubrication & 12. Packaging \\
\hline
\end{tabular}

\begin{tabular}{|c|c|c|}
\hline \multicolumn{3}{|c|}{ Machine } \\
\hline 1. Creel design & 2. Package stabilization & 3. Balloon distance \\
\hline 4. Spacing & 5. Tube condition & 6. Yarn path \\
\hline 7. Pre-tensioning & 8. Clearer design & 9. Feeding system \\
\hline 10. Yarn control & 11. Yarn detectors & 12. Eyelet condition \\
\hline 13. Eyelet design & 14. Feeder plate settings & 15. Feeder density \\
\hline 16. Gauge & 17. Knitting system & 18. Tensioning system \\
\hline 19. Knock-over & 20. Needle/sinker profile & 21. Timing \\
\hline 22. Delay & 23. Gaiting & 24. Ne/gauge \\
\hline 25. Dial height & 26. RPM & 27. Cleaning system \\
\hline
\end{tabular}

Ambient Conditions

\begin{tabular}{|l|l|l|}
\hline 1. Air currents & 2. Temperature & 3. Humidity \\
\hline 4. Lighting & 5. Lay-out & 6. Spacing \\
\hline 7. Cleanliness & 8. House-keeping & 9. Disposition \\
\hline
\end{tabular}

\begin{tabular}{|l|l|l|}
\hline 1. Training & 2. Job load & 3. Availability \\
\hline 4. Procedure discipline & 5. Salary & 6. Enforcement policy \\
\hline 7. Reporting technique & 8. Follow-up & 9. Attitude and morale \\
\hline
\end{tabular}

As a follow-up to the development of Tables that document potential causes, prevention or minimization of lint generation, Miguel was also asked to develop a machine audit sheet that can be used once a week to identify potential problem areas. This audit sheet would document the capability to audit the machine 4 times per month so that trend analysis would outline looming problems. Obviously an audit sheet could also be developed for numerous other factors such as the way raw material (i.e., yarn) is stored and transported or the way inventory supplies are ordered, stored and issued et cetera.

Table 2 illustrates another example of an assignment. In this case Miguel was asked to develop and also group a series of potential causes of needle lines. As was done for Table 1, follow up actions could involve the prioritization of groupings, the development of a listing of prioritized potential remedial or preventative actions and the development of an audit sheet to identify problem areas. 
Table 2: Typical Causes Of Vertical Lines

The Jersey Knitting Company

Raleigh, N. C., 27695

(Miguel Andreu Marin)

Needle Caused

\begin{tabular}{|l|l|l|}
\hline 1. Broken butts & 2. Worn butts & 3. Bent butts \\
\hline 4. Bent stems & 5. Polished stems & 6. Bent hooks \\
\hline 7. Rolled hooks & 8. Broken hooks & 9. Worn hooks \\
\hline 10. Bent latches & 11. Broken latches & 12. Stiff latches \\
\hline 13. Closed latches & 14. Worn latches & 15. Sticking needles \\
\hline 16. Mixed needles & 17. Off-gaiting & 18. Dirty needles \\
\hline 19. Old needles & 20. Dial play & 21. Recycled needles \\
\hline
\end{tabular}

Sinker Caused

\begin{tabular}{|l|l|l|}
\hline 1. Sticking sinkers & 2. Dirty sinkers & 3. Polished sinkers \\
\hline 4. Oily sinkers & 5. Bent sinkers & 6. Mixed sinkers \\
\hline 7. Sinker profile & 8. Sinker play & 9. Sinker age \\
\hline
\end{tabular}

\begin{tabular}{|c|c|c|}
\hline \multicolumn{3}{|c|}{ "Other" } \\
\hline 1. Worn slots & 2. Clogged slots & 3. Contaminated slots \\
\hline 4. Needle crowding & 5. Damaged slots & 6. Needle guidance \\
\hline 7. Machine age & 8. Machine RPM & 9. Metal fatigue \\
\hline 10. Element profiles & 11. Yarn tensions & 12. Fabric tensions \\
\hline 13. Delay interactions & 14. Dial height & 15. Spreader condition \\
\hline 16. Oiling practices & 17. Cleaning practices & 18. Flushing practices \\
\hline 19. Lubricant selection & 20. Storage duration & 21. Machine inactivity \\
\hline 22. Relative humidity & 23. Temperature & 24. Lighting \\
\hline 25. Inventory & 26. Management policies & 27. Re-needling policy \\
\hline 28. Re-sinkering policy & 29. Disposal policies & 30. Element finish \\
\hline 31. Start up policies & 32. Yarn cleanliness & 33. Yarn lubrication \\
\hline 34. Yarn uniformity & 35. Knot quality & 36. Ne/gauge \\
\hline 37. Fabric tightness & 38. Run-in ratio & 39. Structure \\
\hline 40 Fabric backing & 41. Yarn type & 42. Yarn color \\
\hline
\end{tabular}

\section{Summary}

Audit tables are used in several textile technology classes and they present an excellent tool to encourage problem oriented thinking and learning while solving realistic problems. While anecdotal in evidence, many former students present feedback indicating that these exercises stuck with them through their industrial careers and helped them address problems that occur in industry. This indicates an improved retention of the learned material and links the value of the learned topics to life after college. Similar to the experiences in the business simulation, linking class experiences to topics relevant to problems in industry or society improves motivation and the quality of learning.

In addition to making learning more interesting and efficient, inquiry-guided learning also allows the linking of managerial and technical topics within a curriculum and even within one course.

\section{References}

1. Andromeda Training, Inc., Homepage, http://www.income-outcome.com/, 2003.

2. Bransford, J.D. and Stein, B.S., The IDEAL Problem Solver: A Guide for Improving, Thinking, Learning, and Creativity, New York, 1984 
3. Faculty Center for Teaching and Learning (FCTL), Teaching with Inquiry-Guided Learning, Raleigh, NC, 2002.

4. Hassall, T. and Joyce, J., "Coping with case studies: Examinations and reality", Management Accounting, 75 (3), 1997, $62-65$.

5. Hergeth, H., "Income/Outcome ${ }^{\mathrm{TM}}$ Analysis of Regional Differences in Apparel Companies", Proceedings of the Second International Business and Economics Conference (ISBN 87-89695-76-3, paper \#6), San Francisco, CA, January 9 - 12, 2003.

6. Jones, M. and Hergeth, H., "Teaching Marketing and Finance through Entrepreneurship Concepts", Journal of Textile and Apparel Technology and Management, Volume 2, Issue 3, Summer 2002.

7. Klabbers, J.H.G., "The emerging field of simulation and gaming: Meanings of a retrospect", Simulation and Gaming, 32, 2001, 471 - 480.

8. Kriz, W., "Creating effective learning environments and learning organizations though gaming simulation design", Simulation and Gaming, Vol. 34, Nr. 4, December 2003, pp. 495 - 511.

9. Lee, V., "The Uses of Uncertainty in the College Classroom", Teaching Excellence, Vol. 10, Nr. 1, 19981999.

10. Marin, Miguel Andreu, Various Assignments in TT 541, NC State University, Raleigh, 2000.

11. Romme, A. G., Putzel, R., "Designing management education: Practice what you teach", Simulation and Gaming, Vol. 34, Nr. 4, December 2003, pp. 512 - 521.

12. Wiggins, G. and McTighe, J, Understanding by Design, Alexandria, VA, pp. 98 - 133, 1998.

13. Wolfe, J. and Fritzsche, D.J., "Teaching business ethics with management and marketing games", Simulation \& Gaming, 29, 1998, pp. 44 - 59.

\section{Appendix}

Figure 1: Students During The Business Simulation Income/Outcome ${ }^{\text {TM }}$

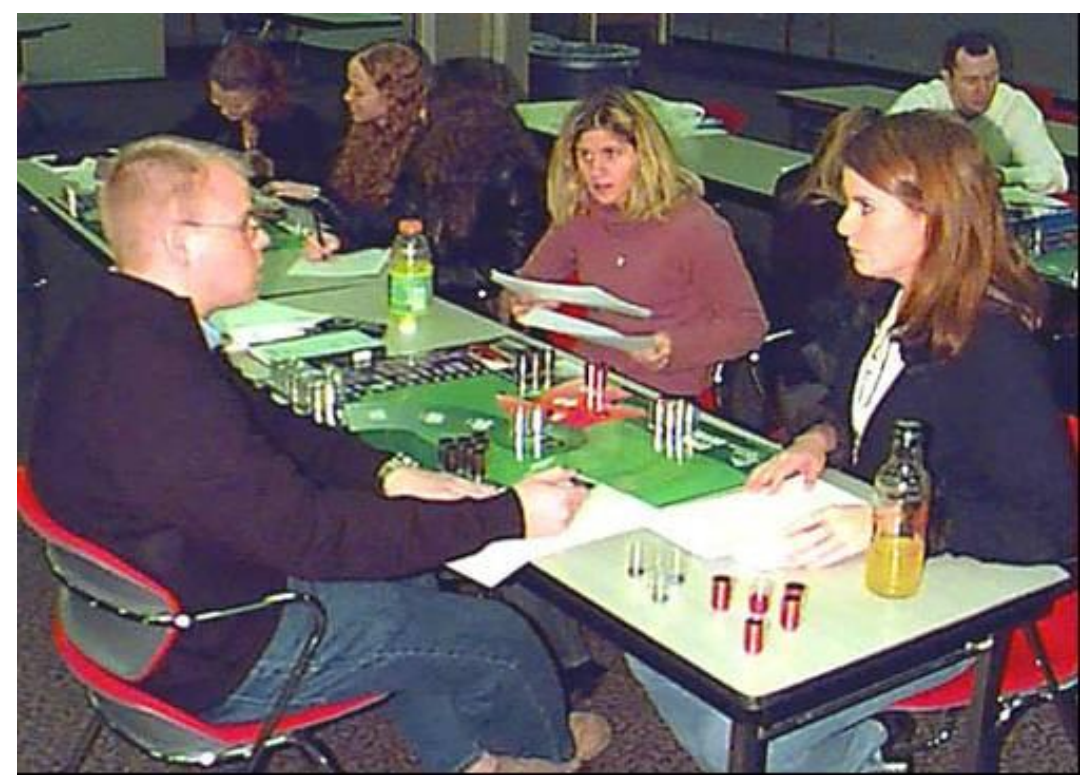


Figure 2: International Paper, Estimate For 2003

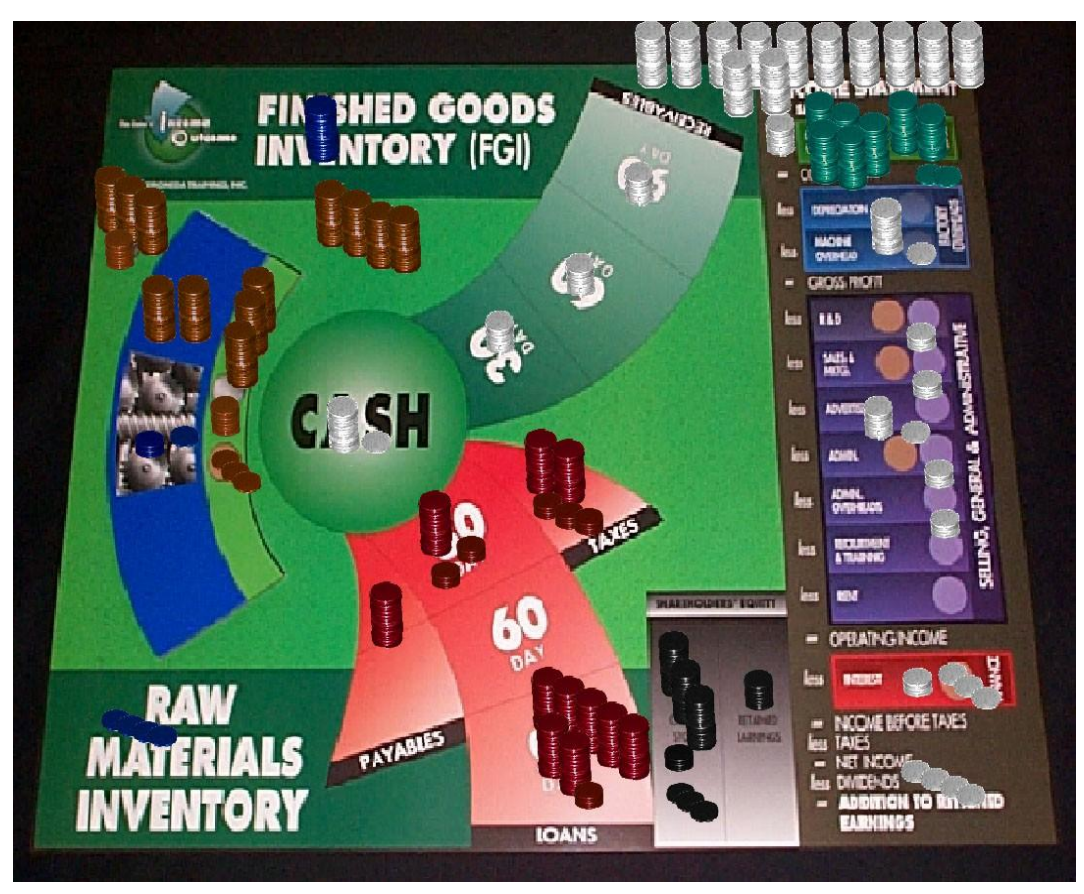

Notes 